\title{
Patient Satisfaction of Ambulatory Care Pharmacy Services in Riyadh City, Saudi Arabia
}

\author{
Yousef Ahmed Alomi ${ }^{1} *$ (D), Hawazen Abdullah Al-Kammash ${ }^{2}$, Aroub Alhamidi², Walaa Aboziad ${ }^{2}$, \\ Kairat Imad Al-Hennawi ${ }^{2}$, M. Mohanad Imad Al-Hennawi², Malika Alshamari ${ }^{3}$, \\ Nahedh Rashed Alotaibi ${ }^{4}$, Nesreen Al-Shubbar ${ }^{5}$ \\ ${ }^{1}$ The Former General Manager of General Administration of Pharmaceutical Care and Head, National Clinical \\ Pharmacy and Pharmacy Practice and Pharmacy R and D Administration, Ministry of Health, Riyadh, KSA. \\ ${ }^{2}$ Clinical Pharmacy Staff, General Administration of Pharmaceutical Care, MOH, Riyadh, KSA. \\ ${ }^{3}$ Head, Pharmacy Services, Alyamma Hospital, Ministry of Health, Riyadh, SAUDI ARABIA. \\ ${ }^{4}$ Head, Pharmacy Services, Aleman Hospital, Ministry of Health, Riyadh, SAUDI ARABIA. \\ ${ }^{5}$ Head, Pharmacy Services, King Salman Hospital, Ministry of Health, Riyadh, SAUDI ARABIA.
}

\section{Abstract}

Purpose: To explore the patient satisfaction of ambulatory care services at Riyadh, Saudi Arabia. Methods: This is a 4-month cross-sectional survey of patient satisfaction of ambulatory care pharmacy services at Riyadh, Saudi Arabia. The survey consisted of 48 questions divided into two parts: the first part collects demographic information and the second part contains questions on 11 domains: (1) medication availability, (2) patient counseling, (3) pharmacist and patient relationship, (4) medication reconciliation, (5) medication aberrance, (6) pharmacy location, (7) pharmacy waiting area, (8) pharmacy communications, (9) pharmacy waiting time, (10) pharmacy recommends to others and (11) overall patient satisfaction of pharmacy services. The survey was distributed to the three hospitals in Riyadh city, included public, pediatrics and emergency hospitals ambulatory care patient. The survey was in an electronic format and it analyze the results through the Survey Monkey system. Results: A total of 606 patients responded to the survey. There were 338 (55.8\%) female and 268 (44.2\%) male responders. Most of them were in age group of $18-44$ years $(65.3 \%)$ without any statistically significant differences in the age groups among the three hospitals $(p<0.5)$. The highest level of education was high school (232 (38.4\%)) followed by the Bachelor's degree (191 (31.6\%)) and an intermediate school (117 (19.4\%)). Most of the patients visited the ambulatory care pharmacy 3 to 4 times in the past 12 months (239 (41.1\%)), whereas the others $(105(18.1 \%))$ visited the ambulatory care pharmacy for the first time. The mean ( \pm standard deviation (SD)) waiting time to get the medications was $18.36 \pm 11.32 \mathrm{~min}$ and there were statistically significant differences among the three hospitals $(p<0.5)$. The average scores of domains 1, 2, 3, 4, 5, 6, 7, 8, 9 and 10 were 3.35, 3.2, 3.7 and 1.96, 1.8, 3.7, 3.25, 2.14, 3.61, 3.54 , respectively. With a total of $381(62.87 \%)$ responders, general evaluation of pharmacy services was found to be very good to excellent, whereas $369(60.9 \%)$ responders recommend the pharmacy to their family or friends and $315(52.5 \%)$ responders prefer to revisit pharmacy. Conclusion: More than half of the patients were satisfied with ambulatory care pharmacy services at Riyadh, Saudi Arabia. Medication reconciliation, medication adherence and pharmacy communication domains were not found to be satisfied. Improving ambulatory care pharmacy services will prevent drug misadventures, avoid additional cost and increase patient satisfaction with pharmacy services.

Key words: Patients, Satisfaction, Ambulatory care services, Riyadh, Ministry of Health, Saudi Arabia.
Received: 14-09-2018;

Accepted: 23-11-2018

*Correspondence to:

Dr. Yousef Ahmed Alomi The Former General Manager of General Administration of Pharmaceutical Care Head, National Clinical Pharmacy and Pharmacy Practice, Head, Pharmacy R and D Administration, Ministry of Health, P.O.BOX 100, Riyadh 11392, Riyadh, Saudi Arabia.

Phone no: +966504417712 Email: yalomi@gmail.com

DOI: 10.5530/ijpcs.2019.8.7

Copyright: ๑ the author(s),publisher and licensee International Journal of Pharmacology and Clinical Sciences. This is an open-access article distributed under the terms of the Creative Commons Attribution Non-Commercial License, which permits unrestricted noncommercial use, distribution, and reproduction in any medium, provided the original work is properly cited.

This is an open access article distributed under the terms of the Creative Commons Attribution-NonCommercial-ShareAlike 4.0 License

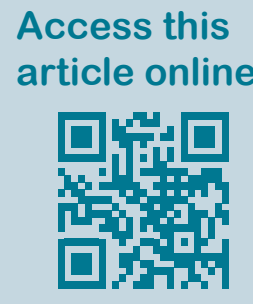

www.ijpcs.net 


\section{INTRODUCTION}

Ambulatory or outpatient pharmacy practice is an essential part of the healthcare system that provides pharmaceutical care to the patients who are not admitted to the hospital. Ambulatory care pharmacists have the responsibility to educate and counsel the patient, assess the patient's need of medication, manage the patient's medication and develop a relationship with the patients and their families. ${ }^{[1]}$ The proper practice of pharmaceutical care in ambulatory care settings results in better outcomes both clinically and economically and better practice might help to serve more patients. [2] Therefore, it is crucial to assess the quality of service provided by the ambulatory care pharmacists and one of the best indicators of quality is to measure patient satisfaction. ${ }^{[3]}$ A strategic plan of pharmaceutical care was published in 2012 at the Ministry of Health $(\mathrm{MOH})$, Saudi Arabia and one of the measurements of follow-up assessment was patient satisfaction with regard to pharmacy services. ${ }^{[4]}$

Worldwide, several studies have measured patient satisfaction of pharmaceutical care services and their primary focus of research was community pharmacy followed by hospital pharmacy. ${ }^{[5-12]}$ A previous study conducted in Saudi Arabia shows patient satisfaction of community pharmacy and another study was conducted on ambulatory care services provided by the hospitals located at Eastern Saudi Arabia. ${ }^{[6,7,9]}$ In addition, there are few studies conducted to validate patient satisfaction in general hospital. ${ }^{[6]}$ Alomi et al. reported on patient satisfaction of pharmaceutical care primary care centers in $2016 .{ }^{[5]}$ In this study, we will focus on measuring the level of patient satisfaction in ambulatory care pharmacies in Riyadh, the capital of Saudi Arabia. To the best of our knowledge there are no studies performed in the region of Riyadh at ambulatory pharmacy services of the $\mathrm{MOH}$ hospitals or any non-MOH governmental and even private hospitals in the Kingdom of Saudi Arabia. Therefore, we aimed to explore the patient satisfaction at ambulatory care services at Riyadh city in Saudi Arabia.

\section{METHOD}

This is a 4-month cross-sectional survey of patient satisfaction of ambulatory care pharmacy services at Riyadh, Saudi Arabia. The survey consisted of 48 questions divided into two parts: the first part collects demographic information and the second part contains questions on 11 domains (1) medication availability, (2) patient counseling, (3) pharmacist and patient relationship, (4) medication reconciliation, (5) medication aberrance, (6) pharmacy location, (7) pharmacy waiting area, (8) pharmacy communications, (9) pharmacy waiting time, (10) pharmacy recommends to others, (11) overall patient satisfaction of pharmacy services. We used the 5-point Likert response scale system to obtain responses. There were close-ended questions. The survey was distributed to three types of ambulatory care hospitals in Riyadh city; included the public, pediatric and emergency hospital type. The public hospital consisted of 300 beds, which will be extended to 500 beds in the future. This hospital has been accredited by the Central Board for Accreditation of Healthcare Institutions at Saudi Arabia. The hospital has adult and neonatal critical care, emergency care and ambulatory care services. It has large specialized ambulatory care diabetic center with different specialties including medical, surgical and pediatrics. The hospital has pharmaceutical care department that caters 24/7. It consists of inpatient pharmacy, ambulatory care and emergency pharmacies. In addition to the drug information center and medication safety services, the pharmacy operates through the computerized physician order system across the departments and units in the hospital. The hospital has emergency care and ambulatory care services with 250 beds meant for pediatrics and maternity, with specialized devices catering to the inpatients, for instance, critical care, obstetrics and gynecology, pediatrics, medical pediatrics and pediatric nephrology. The hospital's pharmacy distributes the medications through unit dose system and a computerized physician order system is followed 24/7. The pharmacy consists of emergency, inpatient and ambulatory pharmacy services. The pharmacy delivers very comprehensive total parenteral nutrition services for neonatal patients, drug information services, medication safety services and total quality management services. The emergency hospital consists of 280 beds, which is expected to expand to more than 500 beds. The hospital consists of great emergency services and neonatal critical care services for adults and pediatrics. It has ambulatory care clinic and inpatient wards for adults' surgical and medical needs. In addition to materiality, medical and pediatric surgery services. The hospital delivers pharmacy services through a very comprehensive computerized physician order entry and unit dose distribution system. The pharmacy consists of inpatient pharmacy, emergency pharmacy and ambulatory care pharmacy services. The pharmacy provides clinical activities through total parenteral nutrition, medications safety and drug information 
services. The authors interviewed the patients with an electronic survey documentation. The study was distributed in an electronic format and the data were analyzed through Survey Monkey system.

\section{RESULTS}

A total of 606 patients responded to the survey. Of them, 509 (84.3\%) were Saudi and 95 (15.7\%) were non-Saudi nationals; there were statistically significant differences in the nationality among three hospitals $(p<0.5)$. There were 338 (55.8\%) female and 268 (44.2\%) male responders; there were statistically significant differences in the sex among the three hospitals $(p<0.5)$. Most of them were in the age group of 18-44 years $(65.3 \%)$; there were no statistically significant differences in the age groups among the three hospitals $(p<0.5)$. The highest level of education of the responders was high school $(232(38.4 \%))$ followed by Bachelor's degree (191 (31.6\%)) and intermediate school (117 (19.4\%)); there was no statistically significant difference between the responders $(p>0.5)$, except with Bachelor degree and diploma degree among the three hospitals $(p<0.5)$. Most of the patients visited the pharmacy 3 to 4 times in the past 12 months (239 (41.1\%)), whereas the others $(105(18.1 \%))$ visited the pharmacy for the first time; the follow-up visit was significantly higher than that of the first visit among the three hospitals $(p<0.5)$. The mean \pm (standard deviation) waiting time to get their medications was $18.36 \pm 11.32$ and there were statistically significant differences among the three hospitals $(p<0.5)$ (Table 1$)$. The average scores of domains $1,2,3,4,5,6,7,8,9$ and 10 were $3.35,3.2,3.7,1.96,1.8,3.7,3.25,2.14,3.61$ and 3.54 , respectively (Table 2 and 3). The general evaluation of pharmacy services was found to be from very good to excellent with 381 (62.87\%) responders, 369 (60.9\%) responders were willing to recommend the pharmacy to their family or friends and 315 (52.5\%) responders preferred to revisit the pharmacy. Most of the patients were satisfied with pharmacy services (265 (48.5\%)), whereas the others were neither satisfied nor happy with pharmacy services $(170(31.1 \%))$. There were statistically significant differences between all the domains among the three hospitals $(p<0.5)$ (Table 3 and 4 ).

\section{DISCUSSION}

In this study, we assessed the patients' opinion about pharmaceutical care in ambulatory care services for four months in the city of Riyadh, Saudi Arabia. The number of responders in all the three hospitals was

\begin{tabular}{|c|c|c|c|c|c|c|}
\hline \multicolumn{7}{|c|}{ No of responders per each hospitals } \\
\hline \multirow[b]{2}{*}{$\begin{array}{l}\text { Answer } \\
\text { Options }\end{array}$} & \multicolumn{3}{|c|}{ Hospitals } & \multirow[b]{2}{*}{$\begin{array}{l}\text { Response } \\
\text { Count }\end{array}$} & \multirow[b]{2}{*}{$\begin{array}{l}\text { Response } \\
\text { Percent }\end{array}$} & \multirow[b]{2}{*}{$\begin{array}{l}P \\
\text { value }\end{array}$} \\
\hline & 1 & 2 & 3 & & & \\
\hline $\begin{array}{l}\text { Hospital } \\
\text { no } 1\end{array}$ & 202 & 0 & 0 & 202 & $33.3 \%$ & $>0.05$ \\
\hline $\begin{array}{l}\text { Hospital } \\
\text { no } 2\end{array}$ & 0 & 237 & 0 & 237 & $39.1 \%$ & \\
\hline $\begin{array}{l}\text { Hospital } \\
\text { no } 3\end{array}$ & 0 & 0 & 167 & 167 & $27.6 \%$ & \\
\hline \multicolumn{4}{|c|}{ Answered questions } & 606 & $100 \%$ & \\
\hline \multicolumn{7}{|c|}{ Nationality } \\
\hline Saudi & 144 & 217 & 148 & 509 & $84.3 \%$ & $<0.05$ \\
\hline Non-Saudi & 57 & 20 & 18 & 95 & $15.7 \%$ & $<0.05$ \\
\hline \multicolumn{5}{|c|}{ Answered questions 604} & $100 \%$ & \\
\hline \multicolumn{7}{|c|}{ Sex } \\
\hline Female & 105 & 151 & 82 & 338 & $55.8 \%$ & $<0.05$ \\
\hline Male & 97 & 86 & 85 & 268 & $44.2 \%$ & $<0.05$ \\
\hline \multicolumn{4}{|c|}{ Answered questions } & 606 & $100 \%$ & \\
\hline \multicolumn{7}{|c|}{ Age } \\
\hline & \multicolumn{3}{|c|}{ Hospitals } & & & \\
\hline $\begin{array}{l}\text { Answer } \\
\text { Options }\end{array}$ & 1 & 2 & 3 & $\begin{array}{l}\text { Response } \\
\text { Count }\end{array}$ & $\begin{array}{l}\text { Response } \\
\text { Percent }\end{array}$ & $\begin{array}{l}P \\
\text { value }\end{array}$ \\
\hline$<18$ & 7 & 12 & 9 & 28 & $4.6 \%$ & $>0.05$ \\
\hline $18-29$ & 56 & 74 & 46 & 176 & $29.0 \%$ & $>0.05$ \\
\hline $30-44$ & 71 & 92 & 57 & 220 & $36.3 \%$ & $>0.05$ \\
\hline $45-59$ & 65 & 59 & 50 & 174 & $28.7 \%$ & $>0.05$ \\
\hline $60+$ & 3 & 0 & 5 & 8 & $1.3 \%$ & $\begin{array}{l}< \\
0.05(2,3)\end{array}$ \\
\hline \multicolumn{4}{|c|}{ Answered question } & 606 & $100 \%$ & \\
\hline \multicolumn{7}{|c|}{ Type of visit } \\
\hline First visit & 53 & 43 & 26 & 122 & $20.4 \%$ & $<0.05$ \\
\hline Followup & 145 & 192 & 138 & 475 & $79.6 \%$ & $<0.05$ \\
\hline \multicolumn{4}{|c|}{ Answered question } & 597 & $100 \%$ & \\
\hline \multicolumn{7}{|c|}{ Average waiting time to get the medications } \\
\hline & 1 & & 2 & 3 & Average & \\
\hline & $\begin{array}{l}\text { Mean } \\
+/ \text { - SD } \\
\text { (minute }\end{array}$ & $\begin{array}{l}M \\
+1 \\
(n\end{array}$ & 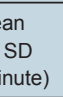 & $\begin{array}{l}\text { Mean +/- SD } \\
\text { (minute) }\end{array}$ & $\begin{array}{l}\text { Mean +/- SD } \\
\text { (minute) }\end{array}$ & \\
\hline & $\begin{array}{l}19.36 \\
+/- \\
11.02\end{array}$ & & $\begin{array}{l}6+/- \\
5\end{array}$ & $\begin{array}{l}24.024+/- \\
14.94\end{array}$ & $\begin{array}{l}18.36+/- \\
11.32\end{array}$ & $<0.05$ \\
\hline $\begin{array}{l}\text { Answered } \\
\text { question }\end{array}$ & 191 & & 236 & 165 & 592 & \\
\hline \multicolumn{7}{|c|}{ Level of education } \\
\hline $\begin{array}{l}\text { Doctorate } \\
\text { degree }\end{array}$ & 0 & 0 & 3 & 3 & $0.5 \%$ & \\
\hline $\begin{array}{l}\text { Master } \\
\text { degree }\end{array}$ & 4 & 2 & 9 & 15 & $2.5 \%$ & \\
\hline $\begin{array}{l}\text { Bachelor } \\
\text { Degree }\end{array}$ & 51 & 93 & 47 & 191 & $31.6 \%$ & $<0.05$ \\
\hline Diploma & 7 & 1 & 5 & 13 & $2.2 \%$ & $<0.05$ \\
\hline High school & 81 & 91 & 60 & 232 & $38.4 \%$ & \\
\hline $\begin{array}{l}\text { Intermediate } \\
\text { School }\end{array}$ & 44 & 44 & 29 & 117 & $19.4 \%$ & \\
\hline $\begin{array}{l}\text { Primary } \\
\text { School }\end{array}$ & 12 & 6 & 12 & 30 & $5.0 \%$ & \\
\hline $\begin{array}{l}\text { Not } \\
\text { educated }\end{array}$ & 2 & 0 & 1 & 3 & $0.5 \%$ & \\
\hline & & & & 604 & $100 \%$ & \\
\hline
\end{tabular}




\begin{tabular}{|c|c|c|c|c|c|c|}
\hline \multirow[b]{2}{*}{ Answer Options } & \multicolumn{3}{|c|}{ Hospitals } & \multirow[b]{2}{*}{$\begin{array}{l}\text { Rating } \\
\text { Average }\end{array}$} & \multirow[b]{2}{*}{$\begin{array}{l}\text { Response } \\
\text { Count }\end{array}$} & \\
\hline & 1 & 2 & 3 & & & \\
\hline \multicolumn{7}{|c|}{ 1. Medication Availability Domain } \\
\hline \multicolumn{7}{|c|}{ 1.1 Have you received all the medications, that has been prescribed to you } \\
\hline & 3.46 & 3.57 & 3.25 & 3.44 & 605 & $<0.05$ \\
\hline \multicolumn{7}{|c|}{ 1.2 You have received a prescription refill of your medicines to continue dispensing from pharmacy directly next months. } \\
\hline & 3.96 & 2.66 & 3.34 & 3.27 & 594 & $<0.05$ \\
\hline \multicolumn{7}{|c|}{ 2. Patient Counseling Domain } \\
\hline \multicolumn{7}{|c|}{ 2.1 All medications you received were packed. } \\
\hline & 4.57 & 4.13 & 4.18 & 4.29 & 601 & $<0.05$ \\
\hline \multicolumn{7}{|c|}{2.2 Instructions were labeled on each medication } \\
\hline & 4.62 & 4.23 & 4.11 & 4.33 & 604 & $<0.05$ \\
\hline \multicolumn{7}{|c|}{2.3 Instructions that contain of: (patient's name, medication's name, medication's strength, and how to use) were written clearly. } \\
\hline & 4.18 & 3.94 & 3.71 & 3.96 & 604 & $<0.05$ \\
\hline \multicolumn{7}{|c|}{ 2.4 The pharmacist provides you written/ or printed information about drug therapy and/or diseases. } \\
\hline & 2.66 & 2.03 & 2.43 & 2.35 & 605 & $<0.05$ \\
\hline \multicolumn{7}{|c|}{ 2.5 The pharmacist Explains to you how to know if medications are working } \\
\hline & 2.49 & 1.92 & 2.25 & 2.20 & 604 & $<0.05$ \\
\hline \multicolumn{7}{|c|}{ 2.6 The pharmacist explains all the possible side effects } \\
\hline & 2.00 & 2.01 & 1.84 & 1.96 & 603 & $<0.05$ \\
\hline \multicolumn{7}{|c|}{ 2.7 The pharmacist provides you information about the proper storage of your medication. } \\
\hline & 2.57 & 2.03 & 2.11 & 2.23 & 603 & $<0.05$ \\
\hline \multicolumn{7}{|c|}{ 2.8 The pharmacist provides you with thorough medication counseling and encourages you to ask questions. } \\
\hline & 3.87 & 3.46 & 2.97 & 3.46 & 604 & $<0.05$ \\
\hline \multicolumn{7}{|c|}{2.9 You understand what pharmacist saying } \\
\hline & 4.38 & 4.20 & 3.83 & 4.16 & 605 & $<0.05$ \\
\hline \multicolumn{7}{|c|}{ Table 4: Patient satisfaction Domains. } \\
\hline \multicolumn{7}{|c|}{ 3. Pharmacist and Patient Relationship Domain } \\
\hline \multicolumn{7}{|c|}{ 3.1 When you're receiving your prescription medications, the pharmacist delivers your medicines in a polite way } \\
\hline & 4.24 & 3.79 & 3.49 & 3.86 & 606 & $<0.05$ \\
\hline \multicolumn{7}{|c|}{ 3.2 Pharmacists have technical skills (thoroughness, carefulness, competence). } \\
\hline & 4.24 & 3.73 & 3.60 & 3.86 & 603 & $<0.05$ \\
\hline \multicolumn{7}{|c|}{ 3.3 All pharmacists characterized with courtesy and respect. } \\
\hline & 3.92 & 3.18 & 3.14 & 3.42 & 604 & $<0.05$ \\
\hline \multicolumn{7}{|c|}{ 3.4 The way the pharmacist answers your questions excellent. } \\
\hline & 4.23 & 3.73 & 3.63 & 3.87 & 602 & $<0.05$ \\
\hline \multicolumn{7}{|c|}{ 3.5 The amount of time the pharmacist spends with you. } \\
\hline & 3.87 & 3.63 & 3.33 & 3.63 & 602 & $<0.05$ \\
\hline
\end{tabular}




\begin{tabular}{|c|c|c|c|c|c|}
\hline \multicolumn{5}{|l|}{ 4. Medication Reconciliation Domain } & \\
\hline \multicolumn{6}{|c|}{ 4.1 Pharmacist uses information about you previous conditions/drugs when assessing your drug therapy. } \\
\hline 2.00 & 1.98 & 1.96 & 1.98 & 601 & $<0.05$ \\
\hline \multicolumn{6}{|c|}{ 4.2 You have received a copy of prescription contains all medications prescribed to you and may use during outpatient } \\
\hline 1.98 & 1.76 & 2.16 & 1.94 & 590 & $<0.05$ \\
\hline \multicolumn{6}{|l|}{ 5. Medication Adherence Domain } \\
\hline \multicolumn{6}{|c|}{ 5.1 Did the pharmacist ask about medication compliance } \\
\hline 1.99 & 1.76 & 2.00 & 1.90 & 606 & $<0.05$ \\
\hline \multicolumn{6}{|c|}{ 5.2 Did the pharmacist follow up you and call you after taking your medications as prescribed } \\
\hline \begin{tabular}{|l|l|} 
& 1.77 \\
\end{tabular} & 1.68 & 1.84 & 1.75 & 604 & $<0.05$ \\
\hline \multicolumn{6}{|l|}{ 6. Pharmacy Location Domain } \\
\hline \multicolumn{6}{|l|}{6.1 Is the pharmacy conveniently located } \\
\hline \begin{tabular}{|l|l|} 
& 4.13 \\
\end{tabular} & 3.40 & 3.77 & 3.74 & 604 & \\
\hline \multicolumn{6}{|l|}{ 7. Pharmacy Waiting Area Domain } \\
\hline \multicolumn{6}{|c|}{7.1 Is the waiting area of pharmacy comfortable, convenient pharmacy lounge? } \\
\hline \begin{tabular}{l|l} 
& 2.77 \\
\end{tabular} & 1.94 & 3.89 & 2.75 & 605 & $<0.05$ \\
\hline \multicolumn{6}{|c|}{ 7.2 The amount of time you have been waiting before seeing a pharmacist was } \\
\hline \begin{tabular}{l|r} 
& 3.77 \\
\end{tabular} & 3.60 & 3.35 & 3.59 & 605 & $<0.05$ \\
\hline \multicolumn{6}{|c|}{ 7.3 The place of pharmaceutical counseling respects your privacy. } \\
\hline \begin{tabular}{l|l} 
& 3.40 \\
\end{tabular} & 4.02 & 2.60 & 3.42 & 604 & $<0.05$ \\
\hline \multicolumn{6}{|l|}{ 8. Pharmacy Communication Domain } \\
\hline \multicolumn{5}{|l|}{ 8.1 Getting through to the pharmacy by phone } & $<0.05$ \\
\hline \begin{tabular}{l|l} 
& 2.18 \\
\end{tabular} & 1.93 & 2.37 & 2.14 & 522 & \\
\hline \multicolumn{6}{|c|}{ 9. Pharmacy Waiting Time Domain } \\
\hline \multicolumn{6}{|c|}{ 9.1 The amount of time it takes to get a prescription filled at your pharmacy. } \\
\hline \begin{tabular}{l|r} 
& 3.74 \\
\end{tabular} & 3.68 & 3.37 & 3.61 & 605 & $<0.05$ \\
\hline \multicolumn{6}{|c|}{ 10. Pharmacy Recommended to other patients Domain } \\
\hline \multicolumn{6}{|c|}{ 10.1 Do you recommend your family and friends to visit the pharmacy? } \\
\hline \begin{tabular}{|l|l|} 
& 3.69 \\
\end{tabular} & 3.56 & 3.35 & 3.54 & 606 & \\
\hline \multicolumn{6}{|c|}{ 11. Overall Patient Satisfaction of Pharmacy Services Domain } \\
\hline \multicolumn{6}{|c|}{ 11.1 Your general evaluation for the pharmaceutical care } \\
\hline \begin{tabular}{|l|l} 
& 3.77 \\
\end{tabular} & 3.63 & 3.55 & 3.66 & 606 & $<0.05$ \\
\hline \multicolumn{6}{|l|}{ 11.2 Your satisfaction about hotline service (937). } \\
\hline 3.75 & 3.88 & 3.30 & 3.57 & 84 & $<0.05$ \\
\hline \multicolumn{6}{|c|}{ 11.3 Prefer to visit the pharmacy again or recommend to your brothers or friends } \\
\hline 3.64 & 3.41 & 3.32 & 3.46 & 600 & $<0.05$ \\
\hline
\end{tabular}

\begin{tabular}{|c|c|c|c|c|c|c|}
\hline \multirow[b]{2}{*}{ Answer Options } & \multicolumn{3}{|c|}{ Hospitals } & \multirow[b]{2}{*}{ Response Count } & \multirow[b]{2}{*}{ Response Percent } & \multirow[t]{2}{*}{$P$ value } \\
\hline & 1 & 2 & 3 & & & \\
\hline Very satisfied & 56 & 4 & 18 & 78 & $14.3 \%$ & $<0.05$ \\
\hline Somewhat satisfied & 73 & 139 & 53 & 265 & $48.5 \%$ & $<0.05$ \\
\hline Neither satisfied nor dissatisfied & 41 & 90 & 39 & 170 & $31.1 \%$ & \\
\hline Somewhat dissatisfied & 4 & 4 & 12 & 20 & $3.7 \%$ & $<0.05$ \\
\hline Very dissatisfied & 4 & 0 & 9 & 13 & $2.4 \%$ & $<0.05$ \\
\hline \multicolumn{5}{|l|}{546} & $100 \%$ & \\
\hline \multicolumn{5}{|l|}{ skipped question } & 60 & \\
\hline
\end{tabular}


almost similar to the number of responders in other studies. ${ }^{[3,8,10-12]}$ Most of the patients were Saudi nationals, which was expected because only a small proportion of non-Saudi residents are allowed to receive healthcare services from governmental sectors. There was a small difference in the male to female ratio, which is almost negligible. Most of the patients were in middle aged (30-44 years), which is the normal age for most of the chronic diseases, whereas the least number of patients was elderly; this may be because of the low compliance of elderly patients with respect to their appointments and usually more education. Waiting time is one of the most important factors regarding patient satisfaction; this domain was found to be significant among the three hospitals, which is related to the differences in the distribution of the organization system and the number of pharmacy staff at each of these hospitals. The waiting time was found to be acceptable as most of the patients preferred to get their medications in less than $30 \mathrm{~min}$; similar results were obtained by another study conducted in Singapore. ${ }^{[12]}$ Regarding medication availability, our results were found to be less than that reported in a previous study conducted in a primary healthcare center in Saudi Arabia. ${ }^{[5]}$ This difference might be because of the small size of primary healthcare center in the previous study. As a result, it is easier to check if the pharmacy requires a new batch of certain medications. ${ }^{[5]}$ Despite the general high rating of pharmacy counseling, there was a low level of satisfaction in areas like explaining the side effects and storage of the medication and their labeling; however, our results are still in the range of those reported in the literature and are better than the study conducted in Ethiopia. ${ }^{[3,8.12]}$ The results regarding pharmacist and patient relationship satisfaction were fairly good and similar in our study, but the results were less than those reported in a national study conducted in the primary healthcare centers. This may be because the number of people in ambulatory care pharmacies is greater than that in the primary healthcare centers and therefore less time spent with each patient. ${ }^{[12]}$ In the area of medication reconciliation, our results were found to be low because this service is not supported at all hospitals and pharmacies yet. However, our results agree with some other studies. ${ }^{[3,5,8,12]}$ The results on pharmacy location, waiting area and waiting time were found to be good as reported in the literature. Moreover, most of the patients expressed their willingness to recommend the pharmacy to their friends and family and they were generally satisfied with the pharmaceutical services. Our results were found to be better than those reported in the literature, which is related to different pharmacy services among the studied cities. ${ }^{[3,5,8,9,12]}$ The results on patient satisfaction were not found to be significantly different among the three studied hospitals. This study was conducted first in Riyadh city and several missing points need to be explored at all three hospitals.

\section{CONCLUSION}

Although patient satisfaction of pharmacy ambulatory care services exceeds more than half of the responders, there were several domains that need to be improved to reach an optimal level of patient satisfaction. This means medication reconciliation, medication adherence, pharmacy communications and patient counseling domains need additional improvement. In future studies, we intend to adjust these parameters and annual monitoring of patient satisfaction will improve the patient's clinical outcomes and prevent drug-related problems at the $\mathrm{MOH}$ hospitals in the Kingdom of Saudi Arabia.

\section{ACKNOWLEDGMENT}

None.

\section{CONFLICT OF INTEREST}

None.

\section{ABBREVIATIONS}

KSA: Kingdom of Saudi Arabia; MOH: Ministry of Health; CBAHI: Saudi Central Board for Accreditation of Healthcare Institutions; USA: United States of America.

\section{ORCID ID}

Yousef Ahmed Alomi (D) https://orcid.org/0000-0003$1381-628 \mathrm{X}$

\section{REFERENCES}

1. BPS. Ambulatory Care Pharmacy. Americn Pharm Assoc. 2013;6:2011-2.

2. Strand LM, Cipolle RJ, Morley PC, Frakes MJ. The impact of pharmaceutical care practice on the practitioner and the patient in the ambulatory practice setting: twenty-five years of experience. Curr Pharm Des. 2004;10(31):3987-4001.

3. Surur AS, Teni FS, Girmay G, Moges E, Tesfa M, Abraha M. Satisfaction of clients with the services of an outpatient pharmacy at a university hospital in northwestern Ethiopia: a cross-sectional study. BMC Health Serv Res. 2015;15(1):229.

4. Alomi YA, Alghamdi SJ, Alattyh RA. Strategic Plan of General Administration of Pharmaceutical Care at Ministry of Health in Saudi Arabia 
2012 - 2022. JPharm Pharm Scien. 2015;1(13):1-8.

5. Alomi YA, Kurdy L, Aljarad Z, Basudan H, Almekwar B. Patient satisfaction of pharmaceutical care of primary care centers at Ministry of Health in Saudi Arabia. J Pharm Pract Community Med. 2016;2(3):79-87.

6. Al-Arifi MN. Patients' perception, views and satisfaction with pharmacists' role as health care provider in community pharmacy setting at Riyadh, Saudi Arabia. Saudi Pharm J. 2012;20(4):323-30.

7. Al-Jumah KA, Hassali MA, Al-Zaagi I. Adaptation and validation of a questionnaire assessing patient satisfaction with pharmacy services in general hospitals. Patient Prefer Adherence. 2014;8:371-5.

8. Al-Jumah KA, Hassali MA, Alzaagi I. Patient Satisfaction with the Health Services Provided by the Pharmacist at a General Hospital in Riyadh, Saudi Arabia. Eur J Pers Centered Healthc. 2014;2(4):517.
9. Alturki M, Khan TM. A study investigating the level of satisfaction with the health services provided by the Pharmacist at ENT hospital, Eastern Region Alahsah, Kingdom of Saudi Arabia. Saudi Pharm J. 2013;21(3):255-60.

10. Oparah AC, Kikanme LC. Consumer satisfaction with community pharmacies in Warri, Nigeria. Res Soc Adm Pharm. 2006;2(4):499-511.

11. Holsclaw SL, Olson KL, Hornak R, Denham AM. Assessment of Patient Satisfaction with Telephone and Mail Interventions Provided by a Clinical Pharmacy Cardiac Risk Reduction Service. J Manag Care Pharm. 2005;11(5):403-9.

12. Tam VHY, Lim MM. Patients' perceptions and expectations of outpatient pharmacy services in a teaching hospital. Int J Pharm Pract. 1997;5(3):128-32.

Cite this article as: Alomi YA, Al-Kammash HA, Alhamidi A, Aboziad W, Al-Hennawi KI, Al-Hennawi MMI, Alshamari M, Alotaibi NR, Al-Shubbar N. Patient Satisfaction of Ambulatory Care Pharmacy Services in Riyadh City, Saudi Arabia. Int J Pharmacol. Clin. Sci. 2019;8(1):32-8. 